\title{
Health policy model: long-term predictive results associated with the management of hepatitis $C$ virus-induced diseases in Italy
}

This article was published in the following Dove Press journal:

ClinicoEconomics and Outcomes Research

19 June 2014

Number of times this article has been viewed

Francesco Saverio

Mennini ${ }^{1,2}$

Andrea Marcellusi ${ }^{1,3}$

Massimo Andreoni ${ }^{4}$

Antonio Gasbarrini ${ }^{5}$

Salvatore Salomone ${ }^{6}$

Antonio $\mathrm{Craxi}^{7}$

'Centre for Economic and International Studies (CEIS) -

Economic Evaluation and HTA

(EEHTA) Faculty of Economics,

University of Rome Tor Vergata,

Rome, Italy; ${ }^{2}$ Institute of Leadership and Management in Health, Kingston University, London, UK; ${ }^{3}$ Department of Demography, University of Rome La Sapienza, Rome, Italy; ${ }^{4}$ Department of Public Health and Cell Biology, School of Medicine, University of Rome Tor Vergata, Rome, Italy; ${ }^{5}$ Gastroenterology Division, Catholic University of the Sacred Heart of Rome, School of Medicine, Rome. Italy; ${ }^{6}$ Department of Clinical and Molecular Biomedicine, Section of Pharmacology and Biochemistry, University of Catania, Catania, Italy; ${ }^{7}$ Gastroenterology Division, University of Palermo, Palermo, Italy

Correspondence: Francesco Saverio Mennini University of Rome Tor Vergata, Via Columbia 2, Rome, Italy Tel +390672595642

Email f.mennini@uniroma2.it
Background: At present, there are no specific nationwide epidemiological studies representing the whole Italian population. This study is aimed at describing the epidemiological and economic burden that $\mathrm{HCV}$ will generate in the next few years in Italy. Furthermore, the impact that future anti-HCV treatments may have on the burden of disease was considered. This analysis was developed for the period 2012-2030 from the perspective of the Italian National Health Service (NHS).

Methods: A published system dynamic model was adapted for Italy in order to quantify the HCVinfected population in terms of disease progression and the associated costs from 1950 to 2030 . The model structure was based on transition probabilities reflecting the natural history of the disease. In order to estimate the efficacy of current anti-HCV treatment strategies for genotypes 1 and 4, the sustained virological response (SVR) rate in registration clinical trials for both boceprevir and telaprevir was estimated. It was assumed that the efficacy for patients treated with peginterferon + ribavirin was equal to the placebo arm of a randomized clinical trial (RCT) relating to boceprevir and telaprevir. For genotypes $2 / 3$ patients it was assumed that treatment efficacy with dual therapy was equal to a SVR rate from the literature. According to the aim of this study, only direct health care costs (hospital admissions, drugs, treatment, and care of patients) incurred by the Italian NHS have been included in the model. Costs have been extrapolated using the published scientific literature available in Italy and actualized with the 2012 ISTAT (Istituto Nazionale di Statistica) Price Index system for monetary revaluation. Three different scenarios were assumed in order to evaluate the impact of future anti-HCV treatments on the burden of disease.

Results: Overall, in Italy, 1.2 million infected subjects were estimated in 2012. Of these, about 211,000 patients were diagnosed, while only about 11,800 subjects were actually being treated with anti-HCV drugs. A reduction of health care costs is associated with a prevalence decrease. Indeed, once the spending peak is reached during this decade (about $€ 527$ million), the model predicts a cost reduction in the following 18 years. In 2030, based on the more effective treatments currently available, the direct health care cost associated with the management of HCV patients may reach $€ 346$ million ( $-34.3 \%$ compared to 2012 ). The first scenario (new treatment in 2015 with SVR $=90 \%$ and same number of treated patients) was associated with a significant reduction in $\mathrm{HCV}$-induced clinical consequences (prevalence $=-3 \%$ ) and a decrease in direct health care expenses, corresponding to $€ 11.1$ million. The second scenario (increase in treated patients to 12,790 ) produced an incremental cost reduction of $€ 7.3$ million, reaching a net decrease equal to $€ 18.4$ million. In the third scenario (treated patients $=16,770$ ), a higher net direct health care cost decrease versus the base-case (€44.0 million) was estimated.

Conclusion: Our model showed that the introduction of new treatments that are more effective could result in a quasi-eradication of $\mathrm{HCV}$, with a very strong reduction in prevalence.

Keywords: chronic hepatitis, cost of illness, forecast, new HCV treatment 


\section{Background}

In 2010, the World Health Organization (WHO) recognized that hepatitis $\mathrm{C}$ virus (HCV) is a major global public health problem. ${ }^{1}$ It is estimated that about $3 \%$ of the world's population is $\mathrm{HCV}$ positive. ${ }^{2}$ The prevalence of the disease varies around the world.

According to the study conducted by the European Centre for Disease Prevention and Control (ECDC), Italy has the highest number of $\mathrm{HCV}$ positive subjects in Europe and the highest death rate from hepatocellular carcinoma (HCC) and cirrhosis. ${ }^{3}$

In fact, chronic $\mathrm{HCV}$ infection is a primary cause of cirrhosis, $\mathrm{HCC}$, and liver transplantation. ${ }^{4} \mathrm{HCV}$ is currently the major etiologic agent in patients needing medical assistance due to chronic hepatic diseases ${ }^{5,6}$ and, as in the rest of the world, is the most common cause of liver transplantation. ${ }^{7}$ However, despite being the only therapeutic treatment for terminal liver disease, transplantation does not treat $\mathrm{HCV}$ infection, and recurrence may take place after transplantation. ${ }^{8}$

At present, there are no specific nationwide epidemiological studies representing the whole Italian population. However, $\mathrm{HCV}$ prevalence has been evaluated in some local or regional studies. ${ }^{9} \mathrm{HCV}$ ribonucleic acid prevalence is normally around $3 \%$ (with an average value of about $6 \%-10 \%$ in a 1940-1949 birth cohort); it is usually lower than $2 \%$ (mean: 1.6\%) in people born in 1950-1959 and tends to decrease in younger people. ${ }^{10}$ In addition to age correlation, the North-South geographical gradient generates a remarkable epidemiological variability. In fact, prevalence is higher in southern regions $(7.3 \%)$ in comparison to central (6.1\%) and northern ones $(1.6 \%) .{ }^{11}$

It is clear that in future, society and the health service will have to face the complications of HCV-induced pathologies, involving a growing demand in liver transplantations and HCC treatments. ${ }^{12}$ The costs of viral hepatitis are high and tend to increase according to disease severity. In addition to the direct costs incurred for disease management, there are indirect costs linked to the loss of productivity due to disability and premature death in patients suffering from the chronic HCV infections. ${ }^{13}$

This study is aimed at describing the epidemiological and economic burden that $\mathrm{HCV}$ will generate in the next few years in Italy. Furthermore, the impact that future anti-HCV treatments may have on the burden of disease was considered. The analysis has been developed for the period 2012-2030 from the perspective of the Italian National Health Service (NHS).

\section{Methods}

A published system dynamic mode ${ }^{14}$ was adapted for Italy in order to quantify the $\mathrm{HCV}$-infected population in terms of disease progression and the associated costs from 1950-2030. The model structure was based on transition probabilities reflecting the natural history of the disease (Figure 1). The time horizon was settled in 19 years (2012-2030) and a lag transition of 1 year was considered. Transition probabilities have been associated with cost variables of each pathological state and related treatment able to predict - in addition to the epidemiological burden - the economic cost incurred by NHS. Further details on the methods used are reported in the appendix of a previous study. ${ }^{14}$

\section{Epidemiological data}

The model predicted the future projection of epidemiological effects, starting from historical data. Data reported by the United Nations in terms of a historical series in the residential Italian population from 1950 to 2012 were used. ${ }^{15}$ In addition to this, the death rates of the Italian population ${ }^{16}$ were taken into account. Therefore, a projection of effects between 2008 and 2030 was calculated on the basis of historical demographic data in which the age of the population was grouped into 5 -year clusters.

The model assumed an incidence rate equal to $0.016 \%$. Furthermore, the predictive model included a redistribution of prevalence data by age and sex. With reference to this parameter, an American model was adjusted to the Italian context using national literature data. ${ }^{17,18}$ Hence, the model was calibrated by comparing the output trend with the age-specific prevalence of $\mathrm{HCV}$ infection (Figure 2).

The number of diagnosed and treated patients in Italy is considerably lower than in the US. Based on published data, it was assumed that in Italy, only $8 \%$ of chronic $\mathrm{HCV}$ patients are currently treated in clinical centers, ${ }^{19}$ and among these diagnosed patients, only $20 \%$ are treated with dual or triple therapy. ${ }^{20}$ Finally, patients were divided by genotypes according to national epidemiological data $^{21,22}$ where a prevalence of $56 \%, 30 \%, 10 \%$, and $5 \%$ in terms of genotypes 1, 2, 3, and 4, respectively, was estimated.

\section{Treatment efficacy}

In order to estimate the efficacy of current anti-HCV treatment strategies in genotype 1 patients, the sustained 


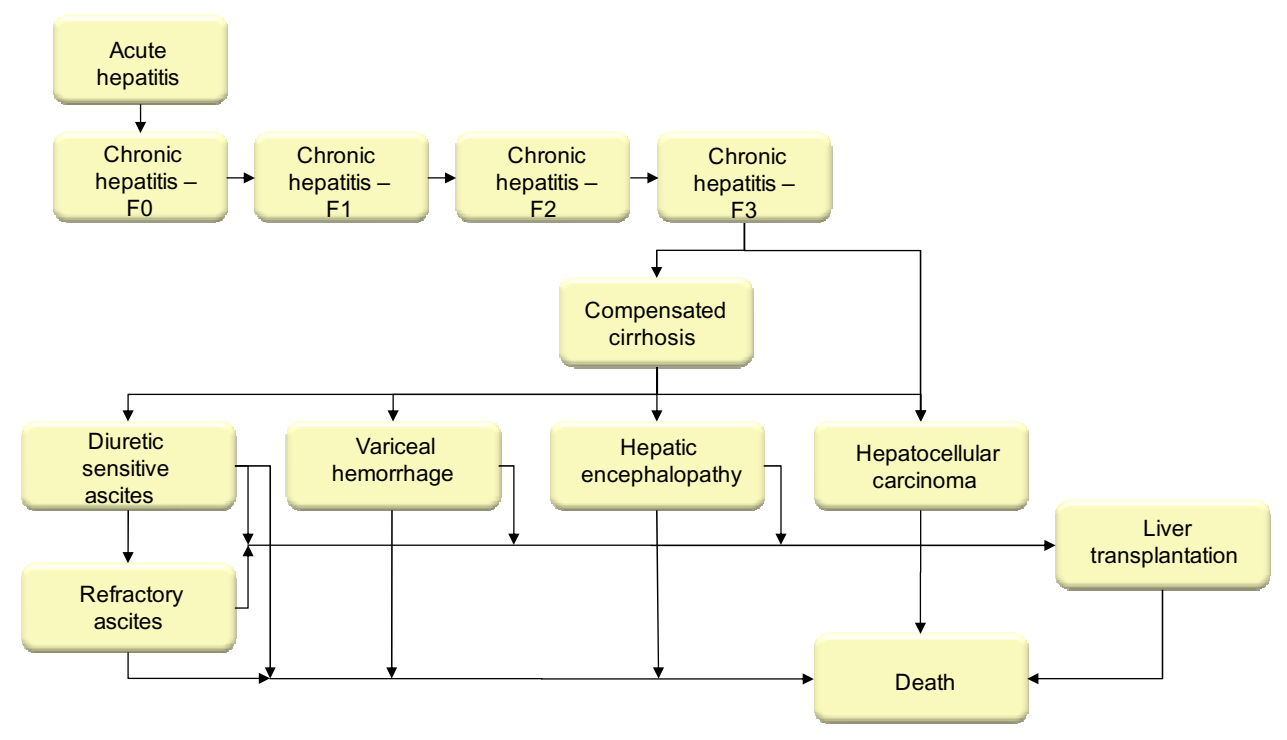

Figure I Forecasting model structure. Data taken from Razavi et al. ${ }^{14}$

virological response (SVR) rate was estimated in registration trials for both boceprevir (70.0\% and $64.4 \%$ in treatmentnaïve and treatment-experienced patients, respectively) and telaprevir (70.0\% in treatment-naïve and $67.4 \%$ in treatment-experienced patients). ${ }^{23-26}$ It was assumed that the efficacy of peginterferon + ribavirin in genotype 1 patients was equal to the placebo arm of a randomized clinical trial (RCT) relating to boceprevir (SVR rate of $36.6 \%$ and $24.2 \%$ in treatment-naïve and treatment-experienced patients, respectively). ${ }^{23,24}$ It was assumed that in genotypes $2 / 3$, treatment efficacy with dual therapy was equal to a SVR rate of $65 \%$ in treatment-naïve patients ${ }^{27}$ and $59 \%$ in treatment-experienced ones. ${ }^{28}$ Finally, it was assumed that the SVR rate for genotype 4 was comparable to that for genotype 1 in this model.

In the base-case, the model assumed that only $10 \%$ of genotype 1 patients eligible for treatment in Italy were treated with boceprevir and telaprevir. The remaining diagnosed patients were assumed to be treated with peginterferon + ribavirin or kept under observation.

\section{Cost data}

According to the aim of this study, only direct health care costs (hospital admissions, drugs, treatment, and care of patients) incurred by the Italian NHS have been included in the model. Table 1 reports direct cost data associated with each health condition. Costs have been extrapolated using the published scientific literature available in Italy and actualized with the 2012 ISTAT (Istituto Nazionale di Statistica) Price Index system for monetary revaluation. ${ }^{29}$ Furthermore, transplantation costs have been estimated using the surgery cost calculated through the Diagnosis Related Group (DRG) reimbursement tariffs ${ }^{30}$ to which the treatment cost following the first year of transplantation has been added. ${ }^{10,31,32}$

In addition to the above reported costs, in chronic $\mathrm{HCV}$ hepatitis and compensated cirrhosis patients, costs associated with dual and triple therapy have been estimated. Table 1 reports input data to estimate treatment costs with dual and triple therapy. The weekly cost of dual therapy has been estimated on the basis of the spending data published in the
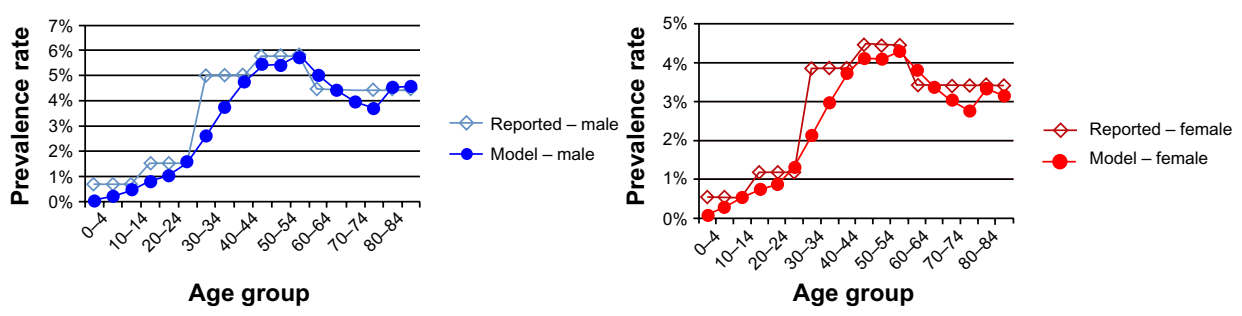

Figure 2 Prevalence by sex and age in Italy, 2012

Note: Data comparison of literature and model estimate taken from Ansaldi et al ${ }^{17}$ and Cozzolongo et al. ${ }^{18}$ 
Table I Direct health care costs associated with health conditions considered in the analysis

\begin{tabular}{llll}
\hline Direct annual costs & $\begin{array}{l}\text { Initial } \\
\text { value }\end{array}$ & $\begin{array}{l}\text { Actualized } \\
\text { cost }\end{array}$ & Reference \\
\hline Chronic hepatitis & $€ 246$ & $€ 288$ & $10,31,32$ \\
Compensated cirrhosis & $€ 347$ & $€ 407$ & $10,31,32$ \\
Decompensated cirrhosis & $€ 5,466$ & $€ 6,409$ & $10,31,32$ \\
Carcinoma & $€ 6,075$ & $€ 7,124$ & $10,31,32$ \\
Transplantation (surgery) & $€ 80,199$ & $€ 80,199$ & 30 \\
Transplantation & $€ 4,729$ & $€ 4,729$ & $10,31,32$ \\
(Ist year treatment) & & & \\
Drug costs & Weekly & Treatment & Reference \\
& cost & (number of & \\
\hline Peginterferone-2a + ribavirin & $€ 283$ & 48 & \\
Peginterferone-2b + ribavirin & $€ 26 I$ & 48 & 20 \\
Boceprevir & $€ 643$ & 35 & 20 \\
Telaprevir & $€ 1,880$ & I2 & 33,34 \\
\hline
\end{tabular}

literature. ${ }^{31}$ For triple therapy, ex-factory prices of boceprevir and telaprevir published in the Official Gazette of the Italian Republic $^{33}$ were used. This price was multiplied by the estimated average number of treatment weeks as given by the European Medicine Agency (EMA) guidelines. ${ }^{34,35}$

\section{Scenario analysis}

The model included three future scenarios and a base-case. The base-case scenario assumed that all eligible patients were treated with peginterferon + ribavirin, and that $10 \%$ of the genotype 1 patients were treated with the most recent protease inhibitors $(50 \%$ with telaprevir and 50\% with boceprevir). In this base-case scenario, it was assumed that no new treatments will be available in Italy, and therefore, the treatment of patients suffering from chronic HCV is not substantially changed. The base-case scenario has been compared with three alternative scenarios, each one including different assumptions, as indicated in Table 2. The assumptions of each scenario have been based on the expert opinion of a clinical board composed by the authors of this work. The scenarios aim to evaluate the epidemiological and economic impact that the new anti-HCV treatments might have from the Italian NHS perspective. In all scenarios, it has been assumed that the cost of the new treatment is comparable to protease inhibitor therapy (conservative assumption).

\section{Sensitivity analysis}

Sensitivity analysis is recommended any time there is uncertainty. ${ }^{36}$ In order to verify the uncertainty of the model results, a probabilistic sensitivity analysis (PSA) ${ }^{37}$ was performed. PSA provides a useful technique to quantify the level of confidence of a decision maker in drawing the conclusions of an economic evaluation. ${ }^{37}$ At each model parameter, a probability distribution (Table 3) was assigned to perform 5,000 Monte Carlo simulations in order to test the robustness of the results and define a $95 \%$ confidence interval (CI) for the data.

\section{Results}

Overall, in Italy, 1.2 million infected subjects were estimated in 2012 . Of these, about 11,800 subjects are actually being treated with anti-HCV drugs.

The virus peak of chronic HCV prevalence was reached during the $1990 \mathrm{~s}$, with the number of infected subjects exceeding 1.8 million (Figure 3A). Thereafter, it is estimated that the total prevalence will decrease until 2030 due to the effect of new treatments currently being used in Italy. In fact, observing the prevalence decrease by HCV sequelae, it is possible to note that cirrhotic patients show a larger drop in prevalence, while more serious pathologies, like HCC and liver transplantation, initially increase and then slightly decrease (Figure 3B).

Table 2 Model parameters by analysis scenario

\begin{tabular}{|c|c|c|c|}
\hline Parameter & Scenario I & Scenario 2 & Scenario 3 \\
\hline Initiation of new treatment & 2015 & 2015 & 2015 \\
\hline Patients eligible for treatment (genotypes) & GI & GI-G4 & GI-G4 \\
\hline Fibrosis status (Metavir score) & $\geq \mathrm{F} 2$ & $\geq \mathrm{F} 2$ & $\geq \mathrm{F} 2$ \\
\hline Rate of eligible patients being treated & $60 \%$ & $80 \%$ & $90 \%$ \\
\hline Rate of patients treated with the new treatment & $\begin{array}{l}10 \%(20 \mid 5) \\
15 \%(20 \mid 6) \\
25 \%(20 \mid 8)\end{array}$ & $\begin{array}{l}10 \%(20 \mid 5), \\
15 \%(20 \mid 6), \\
25 \%(20 \mid 8)\end{array}$ & $\begin{array}{l}15 \%(20 \mid 5) \\
25 \%(20 \mid 6), \\
35 \%(20 \mid 8)\end{array}$ \\
\hline \multirow[t]{2}{*}{ SVR attributed to the new treatment } & $90 \%$ (naïve) & $90 \%$ (naïve) & $90 \%$ (naïve) \\
\hline & $80 \%$ (experienced) & $80 \%$ (experienced) & $80 \%$ (experienced) \\
\hline Compliance to new treatment & $80 \%$ & $80 \%$ & $90 \%$ \\
\hline The number of treated patients is & $\begin{array}{l}\text { Constant over time } \\
(\mathrm{n}=\mathrm{II}, 860)\end{array}$ & $\begin{array}{l}\text { Increased } \\
\text { (from II,860-12,790) }\end{array}$ & $\begin{array}{l}\text { Increased } \\
\text { (from II,860-16,770) }\end{array}$ \\
\hline
\end{tabular}

Abbreviations: $F$, fibrosis grade; G, genotype; $n$, number of subjects; SVR, sustained virological response. 
Table 3 Probabilistic sensitivity analysis parameter (range and distribution)

\begin{tabular}{|c|c|c|c|c|}
\hline & \multicolumn{2}{|l|}{ Range } & \multirow[t]{2}{*}{ Distribution } & \multirow[t]{2}{*}{ Reference } \\
\hline & Min & Max & & \\
\hline \multicolumn{5}{|c|}{ Epidemiological and efficacy parameter } \\
\hline Prevalence rate: male & $2.0 \%$ & $3.5 \%$ & BETA & 17,18 \\
\hline Prevalence rate: female & $2.0 \%$ & $3.5 \%$ & BETA & 17,18 \\
\hline Incidence rate & $0.010 \%$ & $0.020 \%$ & BETA & \\
\hline SVR base-case GI/G4 & $24.0 \%$ & $37.0 \%$ & BETA & $23-26$ \\
\hline SVR base-case G2/G3 & $59.0 \%$ & $65.0 \%$ & BETA & $23-26$ \\
\hline \multicolumn{5}{|l|}{ Annual cost } \\
\hline Chronic hepatitis & $€ 231$ & $€ 346$ & GAMMA & $10,31,32$ \\
\hline Compensated cirrhosis & $€ 325$ & $€ 489$ & GAMMA & $10,31,32$ \\
\hline $\begin{array}{l}\text { Decompensated } \\
\text { cirrhosis }\end{array}$ & $€ 5,125$ & $€ 7,691$ & GAMMA & $10,31,32$ \\
\hline Carcinoma & $€ 5,699$ & $€ 8,548$ & GAMMA & $10,31,32$ \\
\hline $\begin{array}{l}\text { Transplantation } \\
\text { (surgery) }\end{array}$ & $€ 72,175$ & $€ 88,221$ & GAMMA & 30 \\
\hline $\begin{array}{l}\text { Transplantation } \\
\text { (Ist year treatment) }\end{array}$ & $€ 3,784$ & $€ 5,675$ & GAMMA & $10,31,32$ \\
\hline
\end{tabular}

Abbreviations: G, genotype; SVR, sustained virological response; Min, minimum; Max, maximum.

A reduction in health care costs is of course associated with a decrease in prevalence. Indeed, once the spending peak is reached during this decade (about $€ 527$ million), the model predicts a spending reduction in the following 18 years (Figure 3A). In 2030, due to the more effective treatments currently available, the direct health care spending associated with the management of patients suffering from HCV may reach $€ 346$ million ( $-34.3 \%$ compared to 2012 ).

The first scenario was associated with a significant reduction in HCV-induced clinical consequences (prevalence of $-3 \%)$ and a decrease in direct health care expenses corresponding to $€ 11.1$ million (95\% CI: $-€ 7.1$ to $-€ 15.0$ ) (Table 4 and Figure 4). The second scenario produced an incremental cost reduction of $€ 7.3$ million, reaching a net decrease equal to $€ 18.3$ million ( $95 \%$ CI: $-€ 16.2$ to $-€ 20.5$ ).
In the third scenario, a higher net direct health care cost decrease versus the base-case ( $€ 44.0$ million, $95 \%$ CI: $-€ 42.2$ to $-€ 45.8$ ) was estimated.

Moreover, the second scenario almost doubled the reduction of $\mathrm{HCV}$ prevalence $(-5 \%)$, as well as the number of prevented deaths ( $+7.5 \%$ versus the first scenario). However, the third scenario estimated $-11 \%$ in terms of prevalence during the considered follow-up period and a higher number of prevented deaths $(+33.9 \%$ versus the first scenario and $+24.5 \%$ versus the second scenario). Although conservative, all scenarios can be deemed reliable and realistic from the Italian NHS perspective.

\section{Discussion}

Chronic HCV infection is a pathological condition with high economic and social impacts worldwide, particularly in Italy, in which the prevalence is around $2.0 \%-3.5 \%{ }^{17,18}$ The Italian situation is peculiar and ECDC epidemiological analysis shows that this is the highest prevalence rate in Europe. ${ }^{3}$ Unfortunately, these are only estimates and not collected data.

Our study was aimed at dealing with the lack of reliable information on the Italian burden of HCV-induced diseases. Available estimates on $\mathrm{HCV}$ pathologies and the expected epidemiological trend are very limited, if existing at all. Furthermore, the objective was to provide decision makers with fundamental information for reflection and discussion, in order to allow them to plan the implementation of rational and economically sustainable actions aimed at the control and eradication of the infection.

Following its historical evolution, viral HCV infection peaked in the 1990s and decreased in the new millennium. From 2012, the model predicted a steady decrease in prevalence that can be attributed to new available treatments.
A

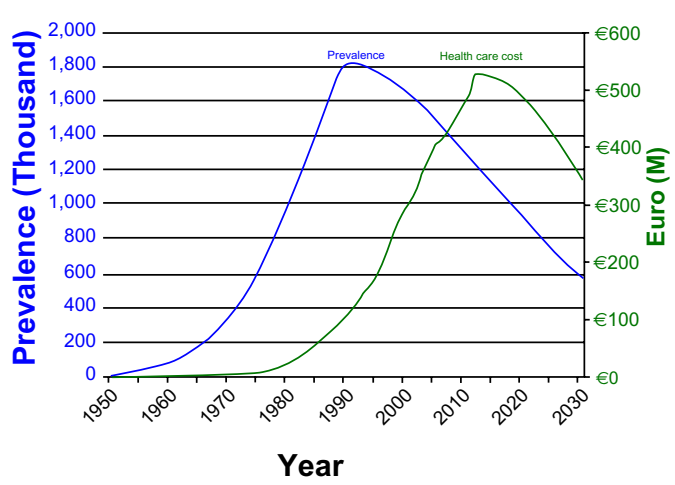

B

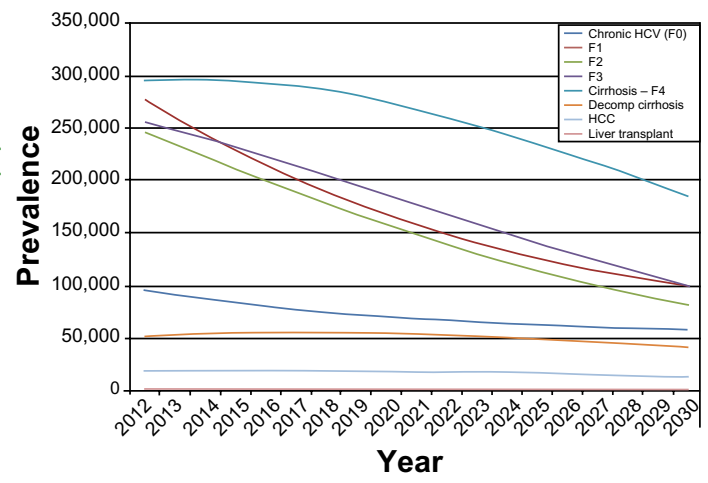

Figure 3 Prevalence estimate and yearly health care costs: Italy base-case.

Notes: (A) Total prevalence and health care costs: Italy 1950-2030; (B) HCV sequelae and total prevalence: Italy 20I2-2030.

Abbreviations: HCC, hepatocellular carcinoma; HCV, hepatitis C virus; F, fibrosis grade; Decomp, decompensated. 
Table 4 Results by analysis scenario and base-case comparison

\begin{tabular}{|c|c|c|c|c|c|c|c|c|}
\hline \multirow{2}{*}{$\begin{array}{l}\text { Scenario I } \\
\text { Prevalence (n) }\end{array}$} & 2012 & & \multicolumn{2}{|c|}{2030 scenario I } & \multicolumn{2}{|c|}{$\begin{array}{l}2030 \text { scenario I vs } \\
2012\end{array}$} & \multicolumn{2}{|c|}{$\begin{array}{l}2030 \text { scenario I vs } \\
2030 \text { base-case }\end{array}$} \\
\hline & $1,242,682$ & & 566,521 & & $-676,161$ & & $-15,688$ & \\
\hline $95 \% \mathrm{Cl}(\min , \max )$ & 917,150 & $\mathrm{I}, 568,2 \mathrm{I} 3$ & 402,842 & 730,200 & $-514,309$ & $-838,013$ & $-9,336$ & $-22,039$ \\
\hline Health care cost (€million) & $€ 527.0$ & & $€ 334.9$ & & $-€ 192.0$ & & $-€|I|$. & \\
\hline $95 \% \mathrm{Cl}(\min , \max )$ & $€ 388$ & $€ 666$ & $€ 232$ & $€ 438$ & $-€ 156$ & $-€ 228$ & $-€ 7.1$ & $-€ \mid 5.0$ \\
\hline Scenario 2 & 2012 & & $2030 \mathrm{scc}$ & io 2 & $\begin{array}{l}2030 \text { sce } \\
2012\end{array}$ & 2 vs & $\begin{array}{l}2030 \mathrm{sce} \\
2030 \mathrm{ba}\end{array}$ & $\begin{array}{l}\text { io } 2 \text { vs } \\
\text { ase }\end{array}$ \\
\hline Prevalence (n) & $1,242,682$ & & 556,323 & & $-686,358$ & & $-25,885$ & \\
\hline $95 \% \mathrm{Cl}(\min , \max )$ & 917,150 & $1,568,213$ & 389,842 & 722,805 & $-527,308$ & $-845,408$ & $-22,336$ & $-29,434$ \\
\hline Health care costs ( $€$ million) & $€ 527.0$ & & $€ 327.6$ & & $-€ 199.3$ & & $-€ \mid 8.3$ & \\
\hline $95 \% \mathrm{Cl}(\min , \max )$ & $€ 388$ & $€ 666$ & $€ 223$ & $€ 432$ & $-€ 165$ & $-€ 234$ & $-€ 16.2$ & $-€ 20.5$ \\
\hline Scenario 3 & 2012 & & $2030 \mathrm{sce}$ & io 3 & $\begin{array}{l}2030 \text { sce } \\
2012\end{array}$ & 3 vs & $\begin{array}{l}2030 \mathrm{sce} \\
2030 \mathrm{ba}\end{array}$ & $\begin{array}{l}\text { io } 3 \text { vs } \\
\text { ase }\end{array}$ \\
\hline Prevalence (n) & $1,242,682$ & & 520,909 & & $-721,772$ & & $-61,299$ & \\
\hline $95 \% \mathrm{Cl}(\min , \max )$ & 917,150 & $1,568,213$ & 348,154 & 693,665 & $-568,996$ & $-874,548$ & $-64,024$ & $-58,574$ \\
\hline Health care costs (€million) & $€ 527.0$ & & $€ 302.0$ & & $-€ 224.9$ & & $-€ 44.0$ & \\
\hline $95 \% \mathrm{Cl}(\min , \max )$ & $€ 388$ & $€ 666$ & $€ 194$ & $€ 410$ & $-€ 194$ & $-€ 256$ & $-€ 42.2$ & $-€ 45.8$ \\
\hline
\end{tabular}

Abbreviations: $\mathrm{Cl}$, confidence interval; $\mathrm{n}$, number of subjects; min, minimum; max, maximum; vs, versus.

A further thrust to the eradication of this disease could be given by the use of new and more effective treatments that, on one hand, would allow us to increase the typology of patients to be treated, and on the other, increase the number of those actually treated. This would allow us to reach two primary objectives for the NHS: to reduce the impact of disease transmission and obtain economic benefits associated with the prevention of dramatically expensive disease complications such as decompensated cirrhosis, HCC, and liver transplantation.
Despite being conservative, the analyzed scenarios have allowed us to evaluate the epidemiological and economic impacts that the new anti-HCV treatments may have from the Italian NHS perspective. The opportunity to treat patients with a higher eligibility rate and therapy compliance, especially at an early stage, is not only ethically indisputable, but also economically efficient (scenario 3 allows better epidemiological and economic performance).

As of today, there are neither national studies that allow us to evaluate the economic burden of $\mathrm{HCV}$-induced pathologies,

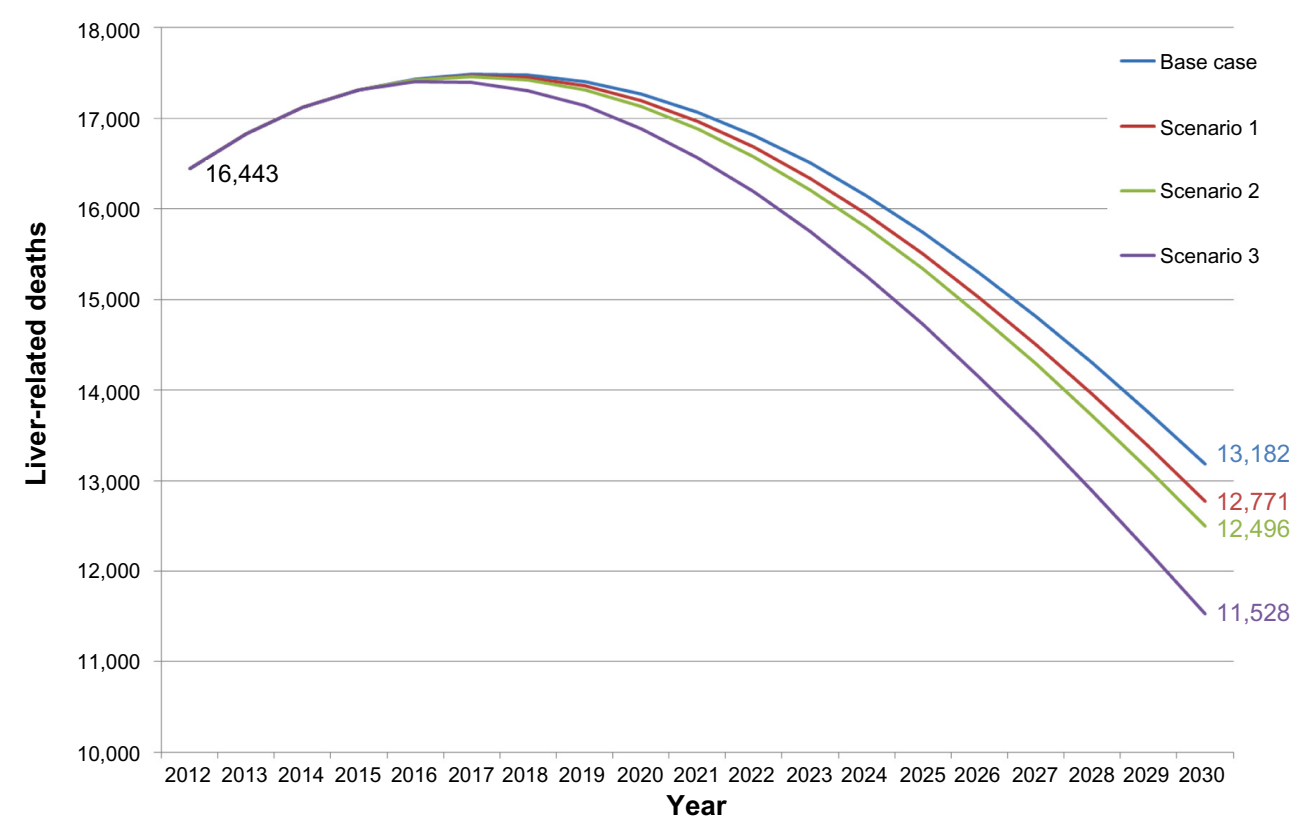

Figure 4 Liver-related deaths of base-case and scenario: Italy 20I2-2030. 
nor studies able to predict their evolution. However, a recent work of Razavi et al ${ }^{14}$ in 2013, from which this study derives, has allowed us to predict the infection evolution of $\mathrm{HCV}$-induced pathologies in the US. In accordance with the American study, in our country, HCV prevalence is bound to decrease, even if with very different age dynamics. The extent of this decrease will be determined by the scenario that future anti-HCV treatments will follow and by the choices of decision makers.

The model has limitations. First of all, epidemiological parameters need to be taken into account. If the shortage of national data makes reliability of results difficult, a model and a systematized method of information, like the one presented in this study, allows us to obtain estimates that are as reliable as possible. Secondly, there is a difficulty in considering further variables that may potentially influence the Italian demographic and social dynamics. Indeed, the model does not take into account any changes in the social behavior of the population, and nor does it consider the possible influence of migratory dynamics or the possible variation of risk factors influencing viral transmission (ie, injection drug use, accidental needlestick injuries, minor nosocomial surgical procedures, acupuncture, tattooing, or piercing). Finally, no monitoring or side effects were considered for anti-HCV drugs, which may cause underestimation of the savings attributable to a better safety of new drugs.

In conclusion, the analysis showed that the introduction of new treatments that are more effective could result in a quasi-eradication of $\mathrm{HCV}$, with a very strong reduction in prevalence. In addition, a large number of lives could be saved from HCV-related deaths accompanied by a large reduction in the number of liver transplantations.

In addition, the model suggests that the potential of new treatments produces significant consequences not only in greater efficiency, but also in terms of security and shorter treatment durations.

All this, according to the logic of economic evaluations, represents a valuable tool for future health policies relating to $\mathrm{HCV}$, and the benefits to health and economics that the new treatments will cause can be ensured in the near future.

We must not forget the great impact in terms of reducing indirect costs (both in terms of reduction of lost productivity, and above all, in terms of the impact on social security and social expenditure, which in Italy is financed by means of public expenditure).

This study does not have the pretension of being or creating a perfect model of epidemiological projection. The objective of this study was to supply data and carefully consider a dialectical confrontation among different professionals involved in the management of patients with $\mathrm{HCV}$-induced chronic infection, and to suggest a valuable tool for future health policy strategy.

\section{Acknowledgments}

Thanks to Homie Razavi and Erin Gower for their technical support. This study was supported with unrestricted funding from Gilead, Italy.

\section{Author contributions}

All authors made substantial contributions to conception and design, acquisition of data, analysis and interpretation of data; drafted the article and revised it critically for important intellectual content; and gave final approval of the version to be published.

\section{Disclosure}

The authors report no conflicts of interest in this work.

\section{References}

1. World Health Organization. Sixty-third World Health Assembly. Viral hepatitis: WHA 63.18. Geneva, Switzerland; May 21, 2010.

2. Lavanchy D. The global burden of hepatitis C. Liver Int. 2009;29 Suppl 1: $74-81$.

3. European Centre for Disease Prevention and Control. Technical Report Hepatitis B and C in the EU neighborhood: prevalence, burden of disease and screening policies. September 2010. Available at: http://www.ecdc. europa.eu/en/publications/Publications/TER_100914_Hep_B_C\%20_ EU_neighbourhood.pdf. Accessed April 14, 2014.

4. Poynard T, Yuen MF, Ratziu V, Lai CL. Viral hepatitis C. Lancet. 2003;362(9401):2095-2100.

5. Gane EJ, Portmann BC, Naoumov NV, et al. Long-term outcome of hepatitis C infection after liver transplantation. $N$ Engl $J$ Med. 1996;334(13):815-820.

6. Sagnelli E, Stroffolini T, Mele A, et al. The importance of HCV on the burden of chronic liver disease in Italy: a multicenter prevalence study of 9,997 cases. J Med Virol. 2005;75(4):522-527.

7. Fagiuali S, Mirante VG, Pompili M, et al; Monotematica AISF 2000OLT Study Group. Liver transplantation: the Italian experience. Dig Liver Dis. 2002;34(9):640-648.

8. Gane E. The natural history and outcome of liver transplantation in hepatitis C virus-infected recipients. Liver Transpl. 2003;9(11):S28-S34.

9. Mariano A, Scalia Tomba G, Tosti ME, Spada E, Mele A. Estimating the incidence, prevalence and clinical burden of hepatitis $\mathrm{C}$ over time in Italy. Scand J Infect Dis. 2009;41(9):689-699.

10. White Book of AISF. Proposal of a National Plan for the Monitoring of Hepatic Diseases: Definition of Environments and Possible Interventions; 2011. Available from: http://www.webaisf.org/media/13891/ libro-bianco-aisf-2011.pdf. Accessed May 13, 2014. Italian.

11. Ansaldi F, Bruzzone B, Salmaso S, et al. Different seroprevalence and molecular epidemiology patterns of hepatitis $\mathrm{C}$ virus infection in Italy. J Med Virol. 2005;76(3):327-332.

12. Mele A, Tosti ME, Spada E, Mariano A, Bianco E, SEIEVA Collaborative Group. Epidemiology of acute viral hepatitis: twenty years of surveillance through SEIEVA in Italy and a review of the literature. Rome: ISTISAN; 2006. Available from: http://www.iss.it/binary/publ/ cont/06-12.1149070762.pdf. Accessed May 19, 2014. 
13. Carosi G, Caporaso N, Gardini I, et al. Epatiti Summit 2010 - A Hidden Emergency: A Comparison of Opinions and Strategies. Available from: http://www.sosfegato.it/camo/onlus/es/Executive_Summary.pdf. Accessed May 13, 2014. 2010. Italian.

14. Razavi H, Elkhoury AC, Elbasha E, et al. Chronic hepatitis C virus (HCV) disease burden and cost in the United States. Hepatology. 2013;57(6):2164-2170.

15. United Nations [webpage on the Internet]. Population Division of the Department of Economic and Social Affairs of the United Nations Secretariat, World Population Prospects: The 2010 Revision and World Urbanization Prospects: The 2010 Revision. New York, NY: United Nations; 2010. Available from: http://esa.un.org/unpd/wpp/unpp/ panel_indicators.htm. Accessed November 1, 2013.

16. UC Berkeley, Max Planck Institute for Demographic Research [webpage on the Internet]. The Human Mortality Database. Rostock, Germany: Max Planck Institute for Demographic Research. Available from: http:// www.mortality.org. Accessed November 1, 2013.

17. Ansaldi F, Bruzzone B, Salmaso S, et al. Different seroprevalence and molecular epidemiology patterns of hepatitis $\mathrm{C}$ virus infection in Italy. J Med Virol. 2005;76(3):327-332.

18. Cozzolongo R, Osella AR, Elba S, et al. Epidemiology of HCV infection in the general population: a survey in a southern Italian town. $A m J$ Gastroenterol. 2009;104(11):2740-2746.

19. Colombo M. How to measure the efficacy of antiviral treatments. The evaluation through "substitute" healing. Second national workshop on economics and drugs in hepatology. WEF-E 2012. Rome, Italy; February 2, 2012. I quaderni di medicina Il 24 ore Sanità Aprile 2012:12-13. Italian.

20. Mariano A, Caserta C, Pendino GM, et al. Antiviral treatment for hepatitis $\mathrm{C}$ virus infection: effectiveness at general population level in a highly endemic area. Dig Liver Dis. 2009;41(7):509-515.

21. Matera G, Lamberti A, Quirino A, et al. Changes in the prevalence of hepatitis $\mathrm{C}$ virus (HCV) genotype 4 in Calabria, Southern Italy. Diagn Microbiol Infect Dis. 2002;42(3):169-173.

22. Marascio N, Matera G, Quirino A, et al. Eleven-year distribution pattern of hepatitis C virus in southern Italy. J Pathog. 2012; 2012:631095.

23. Kwo PY, Lawitz EJ, McCone J, et al; SPRINT-1 investigators. Efficacy of boceprevir, an NS3 protease inhibitor, in combination with peginterferon alfa- $2 \mathrm{~b}$ and ribavirin in treatment-naive patients with genotype 1 hepatitis C infection (SPRINT-1): an openlabel, randomised, multicentre phase 2 trial. Lancet. 2010;376(9742): 705-716.

24. Bacon BR, Gordon SC, Lawitz E, et al; HCV RESPOND-2 Investigators. Boceprevir for previously treated chronic HCV genotype 1 infection. N Engl J Med. 2011;364(13):1207-1217.
25. McHutchison JG, Everson GT, Gordon SC, et al; PROVE1 Study Team. Telaprevir with peginterferon and ribavirin for chronic HCV genotype 1 infection. N Engl J Med. 2009;360(18):1827-1838.

26. Zeuzem S, Andreone P, Pol S, et al; REALIZE Study Team. Telaprevir for retreatment of HCV infection. $N$ Engl J Med. 2011;364(25): 2417-2428

27. Jacobson IM, Brown RS Jr, Freilich B, et al; WIN-R Study Group. Peginterferon alfa- $2 \mathrm{~b}$ and weight-based or flat-dose ribavirin in chronic hepatitis C patients: a randomized trial. Hepatology. 2007;46(4):971-981.

28. Poynard T, Colombo M, Bruix J, et al; Epic Study Group. Peginterferon alfa- $2 \mathrm{~b}$ and ribavirin: effective in patients with hepatitis $\mathrm{C}$ who failed interferon alfa/ribavirin therapy. Gastroenterology. 2009;136(5): 1618-1628. e2.

29. ISTAT. (Italian National Institute of Statistics). Consumer Price Index for Currency Revaluation. Available at: http://rivaluta.istat.it/. Accessed October 1, 2013. Italian.

30. DRG 480. Liver transplantation and/or intestinal transplantation Reimbursement rate - Lazio Region. Italian.

31. Cammà C, Petta S, Enea M, et al; WEF Study Group. Cost-effectiveness of boceprevir or telaprevir for untreated patients with genotype 1 chronic hepatitis C. Hepatology. 2012;56(3):850-860.

32. Ravasio R. Cost efficacy of peginterferon $\alpha-2 \mathrm{a}+$ ribavirin versus peginterferon $\alpha-2 b+$ ribavirin in chronic $C$ hepatitis treatment of HIV co-infected patients. PharmacoEconomics - Italian Research Articles. 2008;10(1):37-47. Italian.

33. Ex-factory Cost AIFA - G.U. n. 287 del 10.12.2012. Available from: http://www.farmacovigilanza.asl3.liguria.it/pdf/determinazione_1_ incivo.pdf. Accessed November 1, 2013.

34. European Medicines Agency. EMA/431387/2011. London, UK: European Medicines Agency; 2012. Available from: http://www.ema.europa.eu/ docs/en_GB/document_library/EPAR_-_Summary_for_the_public/ human/002332/WC500109790.pdf. Accessed November 1, 2013.

35. European Medicines Agency. EMA/644234/2011. London, UK: European Medicines Agency; 2013. Available from: http://www.ema.europa.eu/ docs/en_GB/document_library/EPAR_-_Summary_for_the_public/ human/002313/WC500115507.pdf. Accessed November 1, 2013.

36. Briggs A. Economics notes: handling uncertainty in economic evaluation. BMJ. 1999;319(7202):120.

37. Taylor M. What is sensitivity analysis? Newmarket, UK: Hayward Medical Communications; 2009. Available from: http://www.medicine. ox.ac.uk/bandolier/painres/download/whatis/What_is_sens_analy.pdf. Accessed April 14, 2014.
ClinicoEconomics and Outcomes Research

\section{Publish your work in this journal}

ClinicoEconomics \& Outcomes Research is an international, peerreviewed open-access journal focusing on Health Technology Assessment, Pharmacoeconomics and Outcomes Research in the areas of diagnosis, medical devices, and clinical, surgical and pharmacological intervention. The economic impact of health policy and health systems

\section{Dovepress}

organization also constitute important areas of coverage. The manuscript management system is completely online and includes a very quick and fair peer-review system, which is all easy to use. Visit http://www.dovepress.com/testimonials.php to read real quotes from published authors. 